\title{
Avascular Necrosis of the Femoral Head in a Patient with Behçet's Disease
}

\author{
Behçet Hastalığı Olan Olguda Femurbaşı Avasküler Nekrozu
}

\author{
Murat ERSÖZ, Gülçin URAL, Elif Esen ÖZDEMİR, Selami AKKUŞ \\ ${ }^{1}$ Department of Physical Medicine and Rehabilitation, \\ Ankara Physical Medicine and Rehabilitation Training and Research Hospital, Ankara, Turkey \\ ${ }^{2}$ Department of Physical Medicine and Rehabilitation, Van Training and Research Hospital, Van, Turkey \\ ${ }^{3}$ Department of Physical Medicine and Rehabilitation, Medical Faculty of Yildirım Beyazıt University, Ankara, Turkey
}

Behçet's disease $(\mathrm{BD})$ is a vasculitis characterized by clinical exacerbations and remissions in which various types of blood vessels with different diameters and localizations are involved. ${ }^{[1]}$ Avascular necrosis of the femoral head due to obstruction of the blood vessels may also occur in individuals with $\mathrm{BD}{ }^{[2]}$ Herein, we present a patient with $\mathrm{BD}$ who was suffering from right hip pain and was diagnosed with avascular necrosis of the femoral head. Our goal was to focus attention not only on this diagnosis, but on the use of steroids in this patient group since their usage might have been a triggering mechanism in this patient.

A 66-year-old housewife was admitted to our clinic with right hip pain that had been occurring for eight months. She did not report any fall or trauma. Her pain increased with activity and weight bearing but decreased at rest. She also had pain at night which caused difficulty in sleeping. In addition, the patient reported morning stiffness which lasted for 30 minutes but had no symptoms of arthritis, such as swelling, erythema, or local warmth in any joint, including the right hip. A diagnosis of $\mathrm{BD}$ had been made 10 years earlier due to oral aphthous ulcerations, erythema nodosum, uveitis, episcleritis, and a positive pathergy test., The patient had also experienced headaches, hemifacial spasms, and fever in 2005 and was diagnosed with neuro-Behçet's disease (NBD). She was given immuran $2 \times 50 \mathrm{mg}$ and colchicine $0.5 \mathrm{mg}$ 2x1 daily for three years between 2005-2008 and she was given prednol regularly in exacerbations. She was on amlodipine $5 \mathrm{mg}$ daily therapy for hypertension in admission.

A physical examination revealed an antialgic gait with the right hip in external rotation. The range of flexion and extension of the right hip were normal, but it was painful at the end of the range. Abduction and adduction were painful and limited because of pain in the midrange. Flexion, abduction, external rotation (FABER) and flexion, adduction, internal rotation (FADIR) tests were positive in the right hip, but examinations of other joints and the spine were normal. A neurological examination was normal except for right facial paralysis.

Laboratory investigations, including tests for complete blood count (CBC), erythrocyte sedimentation rate (ESR), C-reactive protein (CRP), and liver function, were normal. Flattening and irregularity on the articular surface of the right femoral head were observed on X-ray. Magnetic

Received: July 02, 2012 Accepted: July 25, 2012

Correspondence: Murat Ersöz, M.D. Ankara Fizik Tedavi Rehabilitasyon Eğitim ve Araştırma Hastanesi Fizik Tedavi ve Rehabilitasyon Kliniği, 06700

Sıhhiye, Ankara, Turkey. Tel: +90 312 - 3103230 e-mail: mursoz@yahoo.com.tr

Presented at the $4^{\text {th }}$ Turkish Congress of Rheumatology, April 07-11, 2010, Antalya, Turkey.

C2013 Turkish League Against Rheumatism. All rights reserved. 
resonance imaging (MRI) of the right hip revealed bone marrow edema in the right femoral head and neck along with bone lesions. This indicated Class B avascular necrosis of the right femoral head in the superior region of the right femoral head with hypointense signal changes in $\mathrm{T}_{1} \mathrm{~A}$-weighted images and iso-hyperintense signal changes in $\mathrm{T}_{2} \mathrm{~A}$ - weighted images with a hypointense rim around it.

The patient was referred to the orthopedic clinic, and right hip replacement was recommended, but she refused surgical treatment. Her complaints diminished after a three-week long, inpatient conservative treatment protocol that included medical and physical therapy combined with an appropriate rehabilitation program. Significant functional progress was achieved over this period as the patient was able to walk with a cane during daily activities.

Avascular necrosis of the femoral head develops as a result of obstruction of blood vessels of the hip bone. ${ }^{[2,3]}$ The most frequent etiological factor is posttraumatic arterial blood supply loss. Steroidal drug use is responsible for the development of osteonecrosis in about $50 \%$ of non-traumatic cases, and $20 \mathrm{mg}$ prednisone daily for 30 days is recommended for this patient group. ${ }^{[4]}$

Avascular necrosis of the femoral head due to obstruction of the blood vessels may occur in individuals with BD. ${ }^{[2,5]}$ Similar to our patient, another study reported a case that developed osteonecrosis of the right femoral head after corticosteroid administration to treat several complications of $\mathrm{BD} \cdot{ }^{[5]}$ We believe that for patients with $\mathrm{BD}$ who are admitted with hip pain, avascular necrosis of the femoral head should be kept in mind along with arthritis, especially in cases that have undergone previous steroid therapy. Since this type of therapy may play a role in the development of avascular necrosis of the femoral head, it should be conducted judiciously in this patient group.

\section{Declaration of conflicting interests}

The authors declared no conflicts of interest with respect to the authorship and/or publication of this article.

\section{Funding}

The authors received no financial support for the research and/or authorship of this article.

\section{REFERENCES}

1. O'Duffy JD. Vasculitis in Behçet's disease. Rheum Dis Clin North Am 1990;16:423-31.

2. Shimizu T, Ehrlich GE, Inaba G, Hayashi K. Behçet disease (Behçet syndrome). Semin Arthritis Rheum 1979;8:223-60.

3. Soucacos PN, Beris AE, Xenakis TH, Malizos KN. Knee osteonecrosis: Distinguishing features and differential diagnosis. In: Urbaniak JR, Jones JP, editors. Osteonekrosis: etiology, diagnosis and treatment. Rosemont, IL: American Academy of Orthopaedic Surgeons; 1997. p. 413-24.

4. Felson DT, Anderson JJ. Across-study evaluation of association between steroid dose and bolus steroids and avascular necrosis of bone. Lancet 1987;1:902-6.

5. Chang HK, Choi YJ, Baek SK, Lee DH, Won KS. Osteonecrosis and bone infarction in association with Behcet's disease: report of two cases. Clin Exp Rheumatol 2001;19:S51-4. 